\title{
Der Patentschutz und das Institut der Zwangslizenz in der Europäischen Union
}

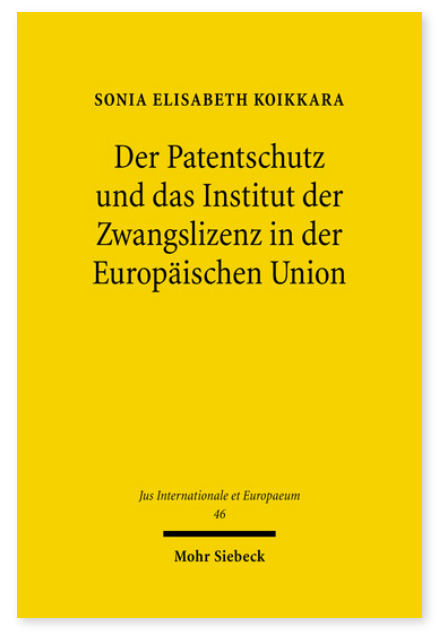

2010. XXII, 235 Seiten. JusIntEu 46

ISBN 978-3-16-151185-1

DOI 10.1628/978-3-16-151185-1

eBook PDF 74,00€

ISBN 978-3-16-150450-1

fadengeheftete Broschur 74,00€
Die in jüngster Zeit diskutierten Probleme des Zugangs zu preiswerteren essentiellen Medikamenten, zu einem auf eine DNASequenz erteilten absoluten Stoffpatent sowie des kartellrechtlichen Zugangs zu einem durch eine Patentlizenzverweigerung blockierten Markt werfen die Frage auf, ob das Unionsrecht durch eine Instrumentalisierung der Zwangslizenz Lösungen bieten kann. Sonia Koikkara untersucht, inwiefern einerseits der Patentschutz in der Europäischen Union materiellrechtlich sowie verfahrensrechtlich gesichert und ausgestaltet ist und andererseits das Unionsrecht die Erteilung von Zwangslizenzen vorsieht.Sie arbeitet insbesondere einen kartellrechtlichen Zwangslizenztatbestand heraus und entwickelt unter Berücksichtigung der internationalen und unionsrechtlichen Vorgaben konkrete Lösungen für die inhaltliche Ausgestaltung, wobei Offenbarungspflicht und Grenzen des Zugriffs auf das Know How im Vordergrund stehen. Schließlich erörtert sie die private Rechtsdurchsetzung dieser kartellrechtlichen Zwangslizenz.

Sonia Elisabeth Koikkara Keine aktuellen Daten verfügbar.

Jetzt bestellen:

https://mohrsiebeck.com/buch/der-patentschutz-und-das-institut-der-zwangslizenz-in-der-europaeischen-union-

9783161511851?no_cache=1

order@mohrsiebeck.com

Telefon: +49 (0)7071-923-17

Telefax: $+49(0) 7071-51104$ 